\title{
Hipertextualidade no Processo Educacional Contemporâneo
}

\author{
Josias Ricardo Hack \\ Professor da graduação em Cinema e \\ da pós-graduação em Linguística da \\ Universidade Federal de Santa Catarina. \\ E-mail: professor.hack@hotmail.com \\ Site: www.hack.ufsc.br
}

\section{Aline Renée Benigno dos Santos Mestre em Linguística pela Universidade Federal de Santa Catarina.}

\section{Reginaldo Amorim de Carvalho}

Mestre em Linguística pela Universidade Federal de Santa Catarina.

\section{Roziane Keila Grando}

Mestre em Linguística pela Universidade Federal de Santa Catarina.

\section{Sebastião Sales Bueno Junior}

Mestre em Linguística pela Universidade Federal de Santa Catarina.
Resumo: As tecnologias atuais estão potencializando a capacidade do homem de transformar o mundo e essas mudanças trazem novidades ao processo educacional contemporâneo. Dentro de tal contexto, o presente artigo tem por objetivo discutir a importância da linguagem hipertextual e dos ambientes virtuais de ensino e aprendizagem na construção do conhecimento. Para tanto, se partirá da definição de hipertexto e na continuidade se fará a exposição de argumentos que referendam a importância da linguagem hipertextual em ambientes que fomentam o ensino e aprendizagem virtual. 0 estudo é caracterizado como uma pesquisa bibliográfica, com uma análise qualitativa do objeto e está ancorado em autores da Educação, assim como da Linguística Textual e da Enunciação.

Palavras-chave: processo educacional; tecnologias; hipertextualidade, ambiente virtual de ensino e aprendizagem.

Abstract: Nowadays the technologies are broadening the opportunities in the educational process. This article analyzes the characteristics of the hypertext language in the virtual learning environment. In order to do that, the text is divided into two chapters: in the first chapter we define hypertext; in the second chapter we discuss the use of the hypertext language in the educational process. This academic study was composed of bibliographical research. The qualitative analysis is based in authors of the Education and the Linguistics.

Keywords: educational process; technologies; hypertext; virtual learning environment.

\section{Introdução}

As tecnologias contemporâneas vêm, a cada dia, transpondo os modos e processos de produção e socialização de uma variada gama de saberes. Transmitir, significar e armazenar estão acontecendo como em nenhum outro momento da história. As formas digitais permitem que as informações sejam criadas de maneira extremamente rápida e flexível, envolvendo diversas áreas do conhecimento sistematizado, bem como o cotidiano nas suas multifacetadas relações. Assim, as tecnologias aportam na sociedade do século XXI como sendo potencializadoras da capacidade do homem de construir, transformar, modificar o mundo, sendo, essencialmente, parte da condição humana.

Com todas essas mudanças, vivenciamos novidades intensas no contexto educativo. Lévy (1993) afirma que a velocidade de evolução dos saberes, a 
massa de pessoas convocadas a aprender e produzir novos conhecimentos e o surgimento de novas ferramentas fazem emergir paisagens inéditas e distintas, identidades singulares no coletivo e uma inteligência e saber coletivos. A produção do conhecimento tecnológico proporciona um novo caminhar no contexto educacional e a explosão de múltiplas tecnologias influencia intensamente o processo de ensino e aprendizagem.

O presente artigo está dividido em três partes e tem por objetivo principal discutir a importância da linguagem hipertextual no processo educativo contemporâneo. Na primeira seção, o leitor encontrará a definição de hipertexto, pela interlocução com alguns autores. Na sequência serão destacadas as características da linguagem hipertextual em ambientes virtuais de ensino e aprendizagem. Por fim, far-se-á algumas considerações sobre os resultados do estudo. A pesquisa é bibliográfica e busca suportes nos estudos linguísticos de base textual e enunciativa em consonância com a educação. A abordagem do objeto, neste caso, a hipertextualidade em relação à educação, é realizada a partir de uma análise qualitativa, a qual busca fazer interpretações das realidades sociais (BAUER; GASKELL, 2007).

\section{O que é hipertexto}

Ao começar a definição por uma leitura etimológica do termo hipertexto, destacase aqui seu radical grego hiper que quer dizer "além". Tal informação é capaz de conduzir o leitor a inferir que esse termo ligado à palavra "texto" configura um possível conceito de que hipertexto seria aquele que quebra uma linearidade instaurada pelo plano comum textual e que se lança numa transcendentalidade materializada por outros textos decorrentes daquele do primeiro plano. Contudo, queremos ir além em nossa definição do termo.

O hipertexto é tão antigo quanto a escrita. As citações e as referências bibliográficas em um texto impresso são exemplos de hipertextualidade, pois elas remetem o leitor a outros textos. No entanto, só damos conta da existência dessa ferramenta quando nos referimos ao ambiente virtual. A diferença está basicamente no suporte. Uma das inovações que surgiram no texto eletrônico são os hiperlinks, que "são dispositivos técnico-informáticos que permitem efetivar ágeis deslocamentos de navegação on-line" e "realizar remissões que possibilitam acessos virtuais do leitor a outros hipertextos de alguma forma correlacionados" (KOCH, 1997: 64). São marcas que ligam um nó a outro, representadas por palavras em negrito, itálico, sublinhado ou cores e ainda ícones ou gráficos. Os hiperlinks podem ser fixos ou móveis e exercem no texto as funções dêitica, coesiva, cognitiva, entre outras.

É na década de 60 que o termo "hipertexto" é cunhado por Ted Nelson, para demonstrar o novo modo de produzir textos, principalmente com o apoio de estudos na área de inteligência artificial. São seguidas propostas do raciocínio associativo, no qual o hipertexto é visto como forma de escrita/leitura não linear, em um sistema de informática. Já na década de 70 , com a chegada do computador pessoal, e na década de 80 , com a internet, o hipertexto foi inserido nos mais diversos contextos sociais (MARTOS, 2001).

Para Koch (1997: 63), o hipertexto é "um suporte linguístico-semiótico". É uma escritura multilinear e multissequencial, que remete o leitor virtual a várias direções dentro de um texto. De acordo com a autora, o hipertexto 
Considerando que um hipertexto remete o leitor a outro(s) texto(s), procuramos ancorar parte da nossa discussão na teoria bakhtiniana dos gêneros do discurso. De acordo com Bakhtin (1992), todas as atividades realizadas pelo ser humano estão relacionadas ao uso da língua, que por sua vez, dá-se através dos enunciados (orais e escritos). Ele ressalta que "cada esfera de utilização da língua elabora seus tipos relativamente estáveis de enunciados", chamados pelo autor de "os gêneros do discurso" (BAKHTIN, 1992: 280). Para Bakhtin, os gêneros discursivos são heterogêneos, devido ao seu tema, a situação no qual eles se concretizam e à composição dos participantes. O autor (BAKHTIN, 1992: 262) afirma também que a riqueza e a multiplicidade dos gêneros do discurso são tantas devido às inesgotáveis "possibilidades da multiforme atividade humana e porque em cada tempo dessa atividade é o repertório dos gêneros do discurso, que cresce e se diferencia à medida que se desenvolve e se complexifica um determinado campo". Na perspectiva bakhtiniana, a função da língua é atender à necessidade do homem de se comunicar, expressar-se. O ouvinte/receptor não recebe a mensagem passivamente, mas ele interage concordando ou não com o seu emissor, de maneira parcial ou total e assim

completa-o, aplica-o, prepara-se para usá-lo etc.; essa posição responsiva do ouvinte se forma ao longo de todo o processo de audição e compreensão desde o seu início, às vezes literalmente a partir da primeira palavra do falante (BAKHTIN, 1992: 271).

O nosso objetivo não é fazer uma abordagem aprofundada sobre a teoria dos gêneros do discurso, mas mostrar a sua (inter)relação com o hipertexto, uma vez que, qualquer texto oral ou escrito, de acordo com o pensamento bakhtiniano, faz parte de algum tipo de gênero discursivo, seja pela sua estrutura ou pela sua função. O intuito é perceber os gêneros discursivos como eventos textuais dinâmicos, maleáveis e plásticos, que se emparelham às necessidades e atividades socioculturais e sociocomunicativas, como as inovações tecnológicas que levaram ao surgimento de hipertextos multimídias (MARCUSCHI, 2009).

Segundo Ramal (2003), a informática transforma o conhecimento em algo não material, flexível, fluido e indefinido, promovendo rupturas pelo próprio usuário, como é o caso da interatividade, a manipulação de dados, o intercâmbio de saberes por meio de nós de rede. Esse novo contexto proporciona o desaparecimento das fronteiras rígidas entre textos-margens e autores-leitores. Os suportes digitais e os hipertextos são as tecnologias intelectuais de que a humanidade passará a ter validade para aprender, interpretar a realidade e transformá-la.

Enfim, o que passa a diferenciar o hipertexto no ambiente virtual da forma impressa é a questão da velocidade, já que um clique sob um link leva menos de um segundo, e as múltiplas interconexões possíveis. Os elos, que são as ligações mantidas entre um nó e outro no ambiente virtual, podem conter tanto um trecho de texto da própria página; um texto em outras páginas localizadas no mesmo computador; um texto em outra página localizada em outro computador qualquer, interligado à internet ou qualquer outra rede de computadores; além de sons, figuras, fotos, vídeos. Assim, os hipertextos estão nas redes nacionais e internacionais de computadores permitindo o acesso às informações da forma mais rápida. Os hipertextos também integram as páginas www - world wide web - presentes na internet, a rede mundial de computadores, possibilitando a conexão em qualquer parte do mundo. Outra forma bastante difundida dos hipertextos eletrônicos são os cd-roms, construídos com fins educacionais, comerciais e de lazer: enciclopédias, jornais, revistas entre outros materiais de referência (MARTOS, 2001).

Em suma, como se percebeu até o momento, a linguagem hipertextual se organiza sem uma linearidade, no sentido de não ter começo, meio e fim. 
Dependendo do caminho que o leitor escolher no hipertexto, ele poderá ver um novo tópico, fornecer informações a mais, mostrar uma referência, exibir uma ilustração, uma foto, um esquema ou ainda um vídeo, ou até mesmo, acionar outro programa no computador que proporcione entrada de informações. $\mathrm{Na}$ sequência continuaremos nossa reflexão agregando outros autores que nos ajudarão a entender as características da linguagem hipertextual em ambientes virtuais de ensino e aprendizagem.

\section{Linguagem hipertextual no processo educacional}

Como já fora comentado na seção anterior, o hipertexto possibilita uma nova forma de leitura: um processo descontínuo e não-linear. Lévy (1999) associa que este evento virtualiza uma função cognitiva, uma atividade mental. Como o pensamento é naturalmente associativo, podemos interpretar que o mecanismo de leitura do hipertexto se apresenta por meio de nós e links. O que o diferencia do texto tido como convencional é seu caráter fragmentado pela idéia de texto escrito canonicamente - rompe com a hierarquia de começo, meio e fim. Muitas vezes, um leitor inicia sua leitura hipertextual onde outro leitor terminou sua leitura. Desta forma podemos admitir que a virtualização do texto, realiza-se de forma interativa com o seu leitor e usuário, pois ao interagir com o mundo virtual os usuários o exploram e o atualizam simultaneamente, é o que podemos chamar de escrita colaborativa. Nessa forma, é possível para o leitor uma (re) textualização diversa e constante, quando o autor pode copiar, inserir, recortar, importar dados, criar links, enfim, editar o seu texto, elevando assim potencial informativo e interacional da linguagem hipertextual (MARTOS, 2001).

Torna-se necessário ressaltar que, nem todas as características do hipertexto são positivas. Segundo Lévy (1999), apesar de o hipertexto no ambiente virtual apresentar a velocidade, ele pode proporcionar problemas e limites, uma vez que, é muito mais fácil nos perdermos na leitura do hipertexto. Martos (2001) defende que isso ocorre, pois, diante da tela, perde-se a referência espacial e sensóriomotora que atua quando se segura um livro na mão. Neste momento, somente se tem acesso uma pequena superfície vinda de outro espaço. Contudo, precisamos lembrar que estas tecnologias sofrem um constante processo de mudança e são estruturadas cada vez mais eficientemente nos termos de tempo, custo e esforço. Litwin (2001) defende que aprender a trabalhar com estas tecnologias implicam em aprender as condições de variação do processo de aperfeiçoamento das TICS.

Visto que a sociedade que comporta os aprendizes de nosso atual sistema educacional se transforma freneticamente, convém ponderarmos sobre como o processo de ensino e aprendizagem se configura perante as mudanças atuais, principalmente àquelas ligadas ao avanço da tecnologia aplicada à educação. Acreditamos que o hipertexto eletrônico deve ser entendido como uma ferramenta para a construção do conhecimento, que oportuniza uma aprendizagem ativa. Em ambientes virtuais de ensino e aprendizagem (AVEA), o leitor vai construindo seu próprio caminho em uma tela interativa, pela própria característica de permitir que se escolha o que seja mais pertinente para sua leitura. Esses indivíduos tornam-se capazes de transformar seus questionamentos acerca do mundo em atos operados por instrumentos simbólicos e materiais.

Para Hack (2010), um AVEA é constituído de ferramentas que objetivam estabelecer relações comunicativas entre os envolvidos no processo de construção do conhecimento. Aos alunos, tal ambiente geralmente disponibiliza recursos que possibilitam:

- O acesso a textos introdutórios aos tópicos, em que o aluno toma conhecimento de quais serão seus desafios em cada unidade que compõe o curso; 
- A administração de alguns aspectos do layout do AVEA;

- A visualização de murais virtuais de notícias e novidades, onde ficam expostos os recados e avisos à turma;

- A participação em fóruns de discussão, no qual acontece o aprofundamento e o debate de temáticas relacionadas ao curso;

- A realização de avaliações on-line e off-line, tais atividades podem ser compostas por questões objetivas, somatórias e discursivas ou podem permitir o envio de trabalhos escritos para uma correção off-line;

- A criação de espaços de colaboração extracurricular, que funcionam como uma espécie de "cafeteria virtual", onde, o aluno pode postar assuntos extraclasse, que interessem os demais envolvidos com o curso;

- A organização de calendários, agendas ou cronogramas de atividades, que são ferramentas utilizadas para ordenar datas de entrega das atividades, prazo para leituras, entre outros;

- A realização de bate-papos virtuais, em chats, que permitem a troca de mensagens entre os membros da turma de forma síncrona;

- O uso de recursos de mensagem instantânea, que permite o diálogo entre as partes envolvidas instantaneamente e deixa um histórico das interações gravado no AVEA;

- O acesso a pastas virtuais onde se encontram os materiais didáticos do curso, como apostilas, slides, gabaritos, leituras complementares, vídeos, áudios dentre outros produtos digitais educativos disponibilizados pelo docente.

Hack (2010) destaca que o professor, tutor ou responsável pela confecção do AVEA possui todos os recursos disponíveis aos alunos, com o acréscimo de duas ferramentas que permitem a edição e o gerenciamento do curso. A pessoa que recebe o papel de editor de um AVEA consegue visualizar ferramentas que criam os hipertextos e demais recursos que comporão o ambiente virtual de estudos. Os editores de AVEA também podem acompanhar o progresso dos alunos em ferramentas que permitem observar estatísticas de acesso e participação nas atividades.

${ }^{1}$ O Sistema UAB foi criado pelo Ministério da Educação (MEC) do Brasil em 2005, sob cinco eixos fundamentais: (1) expansão pública da educação superior, considerando os processos de democratização e acesso; (2) aperfeiçoamento dos processos de gestão das instituições de ensino superior, possibilitando sua expansão em consonância com as propostas educacionais dos estados e municípios; (3) avaliação da educação superior a distância tendo por base os processos de flexibilização e regulação em implementação pelo MEC; (4) contribuições para a investigação em educação superior a distância no país; (5) financiamento dos processos de implantação, execução e formação de recursos humanos em educação superior a distância. (UAB, 2010).
Os cursos de graduação a distância, oferecidos pela Universidade Federal de Santa Catarina (UFSC) dentro do sistema Universidade Aberta do Brasil (UAB) ${ }^{1}$, utilizam o ambiente virtual de ensino e aprendizagem Moodle (Modular ObjectOriented Dynamic Learning Environment), desenvolvido pelo australiano Martin Dougiamas em 1999, considerado um software livre. Professores, tutores, alunos e pessoal administrativo são motivados a fazer todas as interlocuções necessárias utilizando o ambiente virtual. Tal procedimento permite a criação de uma memória histórica virtual do Curso e também serve para o esclarecimento sobre quais encaminhamentos foram dados às dificuldades enfrentadas e levantadas pelos estudantes.

Enfim, como visto aqui, o AVEA pode ser entendido como um sistema de aprendizagem colaborativa e interativa, em que a linguagem hipertextual ajuda os alunos a comunicarem suas idéias e a colaborarem em atividades comuns. Afinal, os integrantes de um AVEA possuem um objetivo em comum e interagem entre si, em um processo no qual o aluno é um sujeito ativo na construção do conhecimento e o educador é um mediador, orientador e condutor do processo educativo. 


\section{Considerações finais}

O presente artigo apresentou o hipertexto como uma ferramenta multissequencial e também um suporte lingüístico-semiótico que permite ao leitor a possibilidade de escolher diferentes direções a partir dos links presentes em um texto no ambiente virtual. A sua relação com os gêneros do discurso está na possibilidade do leitor interagir com diferentes modelos de textos que estão em circulação na nossa sociedade. Na atividade de ensino e aprendizagem, ele contribui tanto para quem estuda quanto para quem faz a mediação do conhecimento, pois abre um leque de possibilidades de pesquisas, além de proporcionar ao usuário um espaço de aprendizagem colaborativa e interativa.

O hipertexto não deve ser considerado como a única ferramenta metodológica a permear o processo educacional contemporâneo, mas precisa ser entendido como capaz de promover, dialogicamente, oportunidades para o crescimento intelectual do discente. Por exemplo, através dos links, os leitores podem trilhar os seus caminhos para chegar aos nós - em que estará o foco da pesquisa, o que se quer pesquisar - e a partir destes nós podem acessar outro e mais outro. Neste sentido, o leitor deixa de fazer leitura em um processo linear e assim tem a oportunidade de navegar, entre um clic e outro, de fazer leituras e de colaborar. Então, podemos inferir que o hipertexto no ambiente virtual possibilita ao usuário a exploração e a atualização de sua leitura em tempo integral, pois lhe permite recortar, copiar, inserir, importar dados e criar links indefinidamente. Mas essas oportunidades devem basear-se em interações significativas, que promovam o desenvolvimento de habilidades e competências a serem aplicadas pelos indivíduos, atores desse processo.

\section{Referências bibliográficas}

BAKHTIN, M. Estética da criação verbal. São Paulo: Martins Fontes, 1992.

BAUER, M. W.; GASKELL, G. Pesquisa qualitativa com texto, imagem e som. 6. ed. Petrópolis: Vozes, 2007.

HACK, J. R. Linguagem virtual e audiovisual na EAD. In.: et al. Produção de materiais autoinstrutivos para a Educação a Distância. Indaial: Asselvi, 2010, p. 59-87.

KOCH, I. V. O texto: construção de sentidos. São Paulo: Contexto, 1997.

LÉVY, P. O que é virtual? Rio de Janeiro: Editora 34, 1999.

LITWIN, E. Das tradições à virtualidade. In: (org). Educação a distancia: temas para o debate de uma nova agenda educativa. Porto Alegre: Artmed, 2001.

MARCUSCHI, L. A. Gêneros textuais: definição e funcionalidade. Disponível em: <http://www.proead.unit.br/professor/linguaportuguesa/arquivos/textos>. Acesso em: 23 out. 2009.

MARTOS, J. Hipertexto e processos comunicacionais na construção do saber a distância. In CABRAL, L. G. et al. Lingüística e ensino: novas tecnologias. Blumenau: Nova Letra, 2001.

RAMAL, A. Educação a distância: entre mitos e desafios. In: ALVES, L.; NOVA, C. (orgs). Educação a distância: uma nova concepção de aprendizado e interatividade. São Paulo: Futura, 2003. p. 87 - 123.

UAB. Universidade Aberta do Brasil. Disponível em: <http://uab.capes.gov.br>. Acesso em 01/2010. 